\title{
ART-Treated Patients Exhibit an Adaptive Immune Response against the HFVAC Peptides, a Potential HIV-1 Therapeutic Vaccine (Provir/Latitude45 Study)
}

\author{
Hervé Fleury ${ }^{1,2, *}$, Sabrina Caldato ${ }^{3}$, Patricia Recordon-Pinson ${ }^{2}{ }^{\circledR}$, Patricia Thebault ${ }^{4}(\mathbb{D}$, \\ Gwenda-Line Guidicelli ${ }^{5}$, Mojgan Hessamfar ${ }^{3}$, Philippe Morlat ${ }^{3}$, Fabrice Bonnet ${ }^{3}$ and \\ Jonathan Visentin ${ }^{5,6}$ \\ 1 Pole de Biologie, CHU de Bordeaux, 33076 Bordeaux, France \\ 2 CNRS UMR 5234, Université de Bordeaux, 33076 Bordeaux, France; patricia.recordon-pinson@u-bordeaux.fr \\ 3 Service de Médecine Interne et Maladies Infectieuses, Hôpital Saint André, CHU de Bordeaux et Université \\ de Bordeaux, ISPED INSERM U 1219, 33076 Bordeaux, France; sabrina.caldato@chu-bordeaux.fr (S.C.); \\ mojgan.hessamfar@chu-bordeaux.fr (M.H.); philippe.morlat@chu-bordeaux.fr (P.M.); \\ fabrice.bonnet@chu-bordeaux.fr (F.B.) \\ 4 Laboratoire Bordelais de Recherche en Informatique (LaBri), Université de Bordeaux, 33400 Talence, France; \\ Patricia.Thebault@u-bordeaux.fr \\ 5 Laboratoire d'Immunologie et Immunogénétique, CHU de Bordeaux, 33076 Bordeaux, France; \\ line-gwenda.guidicelli@chu-bordeaux.fr (G.-L.G.); jonathan.visentin@chu-bordeaux.fr (J.V.) \\ 6 CNRS Immuno ConcEpT, Université de Bordeaux, UMR 5164, 33076 Bordeaux, France \\ * Correspondence: herve.fleury@u-bordeaux.fr
}

Received: 1 October 2020; Accepted: 3 November 2020; Published: 5 November 2020

\begin{abstract}
We proposed a new HIV-1 therapeutic vaccine based on conserved cytotoxic T lymphocyte (CTL) epitopes of archived HIV-1 DNA according to their affinity to the dominant HLA-A and -B alleles of the population investigated. Our proposal (Hla Fitted VAC, HFVAC) was composed of 15 peptides originating from the RT, gag and nef parts of proviral DNA. Our aim was to investigate baseline immune reactivity to the vaccine in HIV-1 chronically infected patients at success of antiretroviral therapy (ART) who would be eligible for a therapeutic vaccine. Forty-one patients were tested. Most of them had been infected with HIV-1 subtype B and all had been receiving successful ART for 2 to 20 years. The predominant HLA-A and -B alleles were those of a Caucasian population. ELISPOT was carried out using the HFVAC peptides. In 22 patients, the PD-1 marker was investigated on CD4+ and $\mathrm{CD} 8+\mathrm{T}$ cells by flow cytometry in order to evaluate global $\mathrm{T}$ cell exhaustion. ELISPOT positivity was $65 \%$ overall and $69 \%$ in patients exhibiting at least one HLA allele fitting with HFVAC. The percentages of CD4+ and CD8+ T cells expressing PD-1 were high (median values 23.70 and 32.60, respectively), but did not seem to be associated with an impairment of the immune response investigated in vitro. In conclusion, reactivity to HFVAC was high in this ART-treated population with dominant HLA alleles, despite potential cellular exhaustion associated with the PD-1 marker.
\end{abstract}

Keywords: HIV-1; vaccine; HFVAC; CTL epitopes; archived proviral DNA; HLA I alleles; PD-1; ELISPOT

\section{Introduction}

Among strategies for a viral cure in patients at success of antiretroviral therapy (ART), HIV-1 therapeutic vaccines have been explored since the initial study of Jonas Salk [1]. With greater understanding of the pathophysiology of the HIV-1 disease, the most promising option has been the stimulation of cytotoxic activity associated with CD8+ cytotoxic $\mathrm{T}$ lymphocytes (CTL) using different vaccine constructs expressing 
CTL epitopes (DNA, recombinant viruses based on MVA, VSV, Ad5, ALVAC canarypox) [2]; other vaccine trials have been designed that were based on peptides such as Vacc-4 [3,4]. However, globally, the results of these approaches have been somewhat disappointing.

The French national agency on AIDS research (ANRS) decided early on to focus on lipopeptides in which peptides are linked to a palmitoyl motif (Lipo5) [5], the lipopeptides being able to be presented to the effective cell through interaction with an HLA allele and the T Cell Receptor (TCR). Our project Provir/Latitude45 is based on this lipopeptide strategy, but our concern was the choice of CTL epitopes, taking into account that viral replication at treatment interruption resumes from archived DNA (while epitopes are generally selected on circulating or reference viruses) and that we must also consider fully the genetic background of the patients and/or the population [6]. We have proposed [7] a multi-epitopic vaccine designed from archived HIV-1 DNA of ART-treated patients and composed of 15 highly conserved peptides with affinity to HLA I alleles A and B, widely expressed in the population investigated (Hla Fitted VACcine: HFVAC). In the present study, we investigated the baseline reactivity to HFVAC of patients at success of ART who would be eligible for a vaccine trial. Enzyme-linked immunosorbent spot assay (ELISPOT) was used, since it is known as a powerful tool to investigate $\mathrm{T}$ cell responses [8].

\section{Materials and Methods}

\subsection{Patients}

Forty-one patients were recruited in the outpatient unit of the Internal Medicine and Infectious Diseases Department of Saint André University Hospital in Bordeaux between January 2019 and January 2020. All were HIV-1 chronically infected individuals under successful ART. They had been recruited in a previous phase of the Provir/Latitude45 project, and data on HLA alleles and archived proviral DNA HIV-1 sequences were available (RT and Prot for all patients, Gag and Nef for some of them). Therefore, we had the identity of the viral subtypes; briefly, HIV-1 subtype B was dominant, followed by unidentified strains, CRF02_AG, unknown recombinant forms (URFs), 1 CRF22_01A1, $1 \mathrm{D}, 1 \mathrm{~F} 1$ and $1 \mathrm{BC}$.

The data on HLA alleles were blinded and the patients were recruited sequentially with no selection based on genetic HLA background. All subjects gave their informed consent for inclusion before they participated in the study and the samples were anonymized. The study was conducted in accordance with the Declaration of Helsinki and the protocol was approved by the Ethics Committee of Sud Ouest and Outremer (DC 2012/48).

\subsection{ELISPOT and Flow Cytometry}

Blood was taken in heparin tubes and used for ELISPOT and flow cytometry. ELISPOT was used to measure the numbers of IFN- $\gamma$-producing PBMCs directed against HIV- 1 epitopes and expressed as spot-forming units (SFUs). It was performed according to the Human IFN- $\gamma$ single-color enzymatic ELISPOT protocol of C.T.L. Europe (Bonn, Germany) on microplates with 200,000 fresh PBMCs/well using pool A (15 HIV-1 peptides of HFVAC) and pools B1, B2 and B3 consisting of subgroups of pool A. The peptides and their affinity to HLA alleles A or/and B are presented in Table 1; the theorical MHC $\mathrm{IC}_{50}$ are given using the IEDB analysis resource. Phyto-hemagglutinin (PHA, positive control) and a peptide pool (CEF) consisting of $23 \mathrm{MHC}$ class-restricted viral peptides from human CMV, EBV and influenza virus were used as positive controls. The negative controls were RPMI $+/-0.4 \%$ DMSO and MOG (a mixture of 29 peptides of myelin oligodendrocyte glycoprotein). The number of SFUs was measured in a C.T.L. automated ImmunoSpot analyzer; the positivity threshold for each peptide pool or antigen was set at $30 \mathrm{SFUs} / 10^{6} \mathrm{PBMCs}$. At least $85 \%$ of cells responding with this methodology are CD8+ T cells, but all studies were conducted with unfractionated PBMCs. 
Table 1. HIV-1 peptides of Hla Fitted VACcine (HFVAC) and their presenting HLA alleles. Pool A contained all peptides while pools B1, B2 and B3 contained subgroups of pool A. The theorical MHC $\mathrm{IC}_{50}$ is noted in the brackets. All MHC $\mathrm{IC}_{50}$ theorical values were $<500 \mathrm{nM}$, with the exception of Nef(134-143)/HLA-A*24:02; this couple peptide/allele has been selected because it is considered in the CTL/CD8+ epitope table of the HIV molecular immunology database (hiv.lan.gov).

\begin{tabular}{|c|c|c|}
\hline Pool & Epitope Identification & Class I Allele(s) with High Affinity to Epitope \\
\hline A & 15 peptides & \\
\hline \multirow{5}{*}{ B1 } & RT (181-189) & HLA-A*02:01(11.5 nM) \\
\hline & RT (158-166) & HLA-A*03:01(12.8 nM), $A^{*} 11: 01(8.3 \mathrm{nM}), A^{*}: 68: 01(176.2 \mathrm{nM})$ \\
\hline & RT (110-118) & HLA-A*68:02(20.2 nM) \\
\hline & RT (163-171) & HLA-B*15:01(24.8 nM) \\
\hline & Gag $(433-440)$ & HLA-A*02:01(12.5 nM) \\
\hline \multirow{5}{*}{ B2 } & RT (227-234) & HLA-A*02:01(17.7 nM) \\
\hline & RT (73-82) & HLA-A*03:01(20.3 nM), $A^{* 11: 01(40.8 n M)}$ \\
\hline & RT (156-164) & HLA-B*07:02(9 nM), B*35:01(43.5 nM) \\
\hline & Gag $(362-370)$ & HLA-A*02:01(5.9 nM) \\
\hline & Nef (134-143) & HLA-A*24:02(558.3 nM), A*29:02(144.8 nM) \\
\hline \multirow{5}{*}{ B3 } & RT (232-241) & HLA-A*02:01(43 nM) \\
\hline & RT (240-249) & HLA-A*11:01(17.1 nM), A*68:01(75.9 nM) \\
\hline & RT (18-26) & HLA-B ${ }^{*} 08: 01(41.5 \mathrm{nM})$ \\
\hline & RT (107-115) & HLA-A*29:02(90.2), HLA-B*35:01(21.8 nM) \\
\hline & Gag (148-156) & HLA-B*07:02(37.3 nM) \\
\hline
\end{tabular}

Flow Cytometry

All patients were routinely followed for their T cell populations using CD45/CD3/CD4/CD8 staining and determination of their absolute counts (BD Multitest CD3/CD8/CD45/CD4 used with BD Trucount Tubes, acquired on a BD FACS Lyric, BD Biosciences). The last 22 included patients were also studied for PD-1 expression by CD4+ and CD8+ T cells acquired on a Fortessa cytometer (BD Biosciences, Franklin Lakes, NJ, USA).

\subsection{Statistical Analysis}

Welch's t-test was used to determine the $p$-value for comparing the means of CD4+ PD-1+ and CD8+PD-1+ T cells (after checking the normal distributions) when analyzing whether there was reactivity to HFVAC peptides.

\section{Results}

\subsection{Patient Characteristics, Lymphocyte Immunophenotyping and PD-1 Expression}

The patients had been treated by ART for 2 to 20 years at entry to the study. Their viral load was below 50 copies/mL the day of ELISPOT assay, with the exception of SA0118 (1590 copies, but $<50$ copies/mL three weeks later) and SA0151 (94 copies/mL). The results of lymphocyte immunophenotyping and PD-1 expression are presented in Table 2; the median values for CD4+ and CD8+ T cells were 548 and $541 / \mu \mathrm{L}$, respectively, while PD-1 marker was expressed by $23.70 \%$ and $32.90 \%$ of CD4+ and CD8+ T cells, respectively. The nadir of CD4+ T cells ranged from 3 to $663 / \mu \mathrm{L}$ (median: $232 / \mu \mathrm{L}$ ). 
Table 2. Median values, 1st and 3rd quartiles for total lymphocyte count, T CD4+, T CD8+, T CD4+ PD-1+ and T CD8+ PD-1+ cells. Total lymphocytes, T CD4+ and T CD8+ cell counts were obtained for 41 patients, while $\mathrm{PD}-1$ expression was investigated in 22 samples.

\begin{tabular}{cccc}
\hline & Median & Q1 & Q3 \\
\hline Lymphocytes & $1685 / \mu \mathrm{L}$ & $1314 / \mu \mathrm{L}$ & $2090 / \mu \mathrm{L}$ \\
\hline CD4+ & $548 / \mu \mathrm{L}$ & $460 / \mu \mathrm{L}$ & $742 / \mu \mathrm{L}$ \\
\hline CD8+ & $541 / \mu \mathrm{L}$ & $331 / \mu \mathrm{L}$ & $848 / \mu \mathrm{L}$ \\
\hline CD4+/CD8+ & 1 & 0.8 & 1.7 \\
\hline CD4+ PD-1+ among CD4+ T cells & $23.70 \%$ & $19.70 \%$ & $29.80 \%$ \\
\hline CD8+ PD-1+ among CD8+ T cells & $32.90 \%$ & $28.33 \%$ & $38.98 \%$ \\
\hline
\end{tabular}

Therefore, the population studied was composed of HIV-1 chronically infected patients under successful ART. About one third of CD8+ T cells in these patients were expressing the PD-1 marker. We then aimed at evaluating the reactivity of these T cells to HFVAC by ELISPOT.

\subsection{ELISPOT Reactivity According to HLA Alleles, Archived Viral Sequences and PD-1 Expression}

ELISPOT data and HLA alleles are presented in Table 3.

Regarding ELISPOT reactivity to HFVAC peptides, four samples were undetermined (thereafter excluded from the analysis), 13 were negative (35\%) and 24 were positive (65\%). In the event of positivity in pool A, pool B1 was more frequently reactive, therefore allowing to hypothesize that it contained immune-dominant peptides. Regarding HLA alleles for presentation of the peptides, all patients but two (SA0110 and SA0127) exhibited at least one allele compatible with presentation of an HFVAC peptide; for these patients expressing fitting alleles, the percentage of reactivity was $69 \%$. The number of HLA-A and -B alleles fitting HFVAC was 1 for 13 patients, 2 for 11 patients, 3 for 9 patients and 4 for one patient (homozygous alleles were counted two times; one patient had no HLA-B typing). Figure 1 shows that the proportion of positive patients increased with the number of HLA alleles allowing the presentation of the HFVAC peptides.

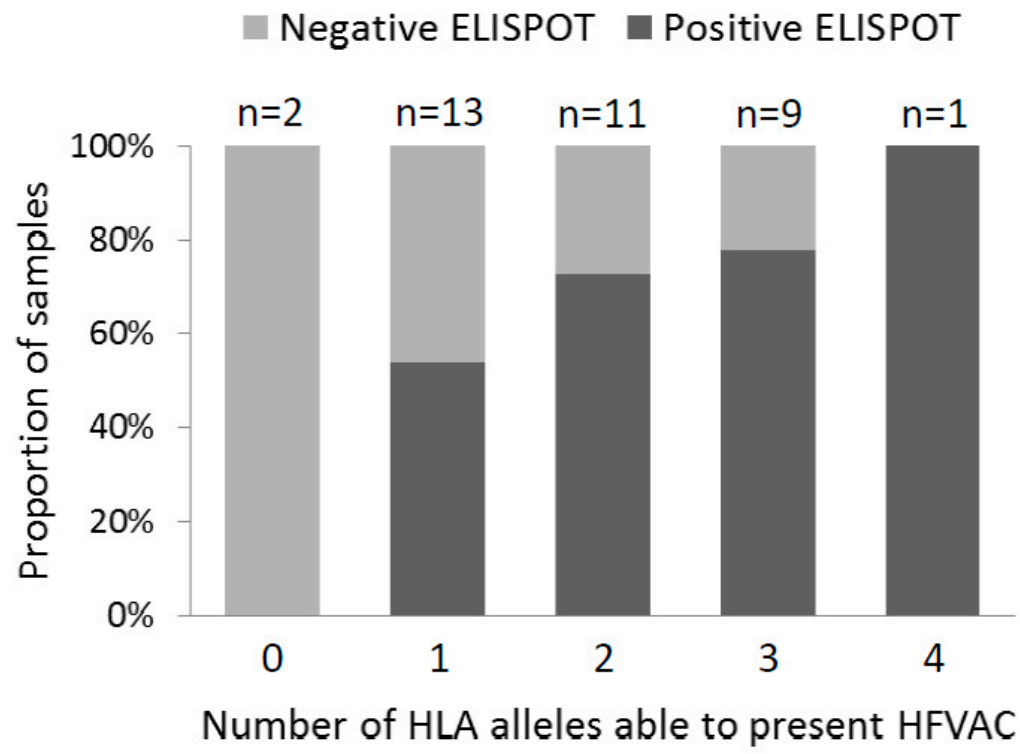

Figure 1. ELISPOT reactivity to HFVAC peptides according to the number of HLA-A and -B alleles fitting with their presentation. 
Table 3. ELISPOT results according to HLA alleles expressed by the patients. The table shows quantitative data of ELISPOT assay in SFUs $/ 10^{6}$ PBMC according to the peptide pool used: A, pool of 15 peptides; B1, B2 and B3 were subpools, as described in Table 1 . The positivity threshold was set at 30 SFUs/ $10^{6}$ PBMC. Underlined and bolded alleles are those showing high affinity for one or several peptides of pool A. ND: not determined (negative control MOG showed more than $30 \mathrm{SFUs} / 10^{6} \mathrm{PBMC}$ ). HLA-B typing of patient SA0122 was not available.

\begin{tabular}{|c|c|c|c|c|c|c|c|}
\hline \multirow{2}{*}{ Patient ID } & \multicolumn{4}{|c|}{ ELISPOT Results (SFUs $/ 10^{6}$ PBMC) } & \multirow{2}{*}{$\begin{array}{l}\text { ELISPOT } \\
\text { Results }\end{array}$} & \multirow{2}{*}{$\begin{array}{l}\text { Peptide } \\
\text { Presentation }\end{array}$} & \multirow[t]{2}{*}{ HLA-Typing } \\
\hline & Pool A & Pool B1 & Pool B2 & Pool B3 & & & \\
\hline SA0107 & $<30$ & $<30$ & $<30$ & $<30$ & Negative & Yes & $\frac{A^{* 29: 02, * 68: 01} ;}{B^{* 58: 02, * 81: 01}}$ \\
\hline SA0108 & 460 & $<30$ & 380 & $<30$ & Positive & Yes & $A^{* 02: 01, * 24: 02, B * 07: 02,}$ \\
\hline SA0109 & 60 & $<30$ & 65 & $<30$ & Positive & Yes & $\begin{array}{l}\mathbf{A}^{* 03: 01},{ }^{*} 23: 01 ; \\
\overline{\mathbf{B}^{* 07: 02}}, * 58: 01\end{array}$ \\
\hline SA0110 & $<30$ & $<30$ & $<30$ & $<30$ & Negative & No & $\begin{array}{l}\overline{\mathrm{A}^{*} 02: 05}, * 26: 01 ; \\
\mathrm{B}^{*} 49: 01, * 55: 01\end{array}$ \\
\hline SA0111 & $<30$ & $<30$ & $<30$ & $<30$ & Negative & Yes & $\frac{A^{*} 03: 01}{B^{*} 38: 01}, * 26: 01 ;$ \\
\hline SA0116 & $<30$ & $<30$ & $<30$ & $<30$ & Negative & Yes & $\frac{A^{* 02: 01}}{\mathrm{~B}^{*} 27: 05}, * 26: 01 ;$ \\
\hline SA0117 & $<30$ & $<30$ & $<30$ & $<30$ & Negative & Yes & $\begin{array}{l}A^{* 24: 02,{ }^{*} 29: 02} ; \\
\mathbf{B}^{* 15: 01}, * 51: 01\end{array}$ \\
\hline SA0118 & $<30$ & $<30$ & $<30$ & $<30$ & Negative & Yes & $\frac{\overline{A^{*} \mathbf{0 2 : 0 1}}, * 68: 02}{\overline{B^{* 53: 01}, * 58: 01}}$ \\
\hline SA0119 & $<30$ & $<30$ & $<30$ & $<30$ & Negative & Yes & $A^{*} 03: 01,{ }^{*} 68: 01 ; B^{*} 58: 02,-$ \\
\hline SA0120 & $<30$ & $<30$ & $<30$ & $<30$ & Negative & Yes & $\begin{array}{l}\mathrm{A}^{*} 02: 05,{ }^{*} 11: 01 \\
\mathrm{~B}^{*} 35: 03,{ }^{*} 50: 01\end{array}$ \\
\hline A0121 & $<30$ & $<30$ & $<30$ & $<30$ & Negative & Yes & $\begin{array}{l}\mathrm{A}^{*} 01: 01,{ }^{*} 26: 01 ; \\
\mathbf{B}^{* 08: 01},{ }^{*} 14: 01\end{array}$ \\
\hline SA0122 & 55 & $<30$ & $<30$ & $<30$ & Positive & Yes & $\overline{A^{*} 02: 01}, * 24: 02$ \\
\hline SA0123 & $<30$ & $<30$ & $<30$ & $<30$ & Negative & Yes & $\begin{array}{l}\overline{A^{*} 24: 02}, * 32: 01 \\
\mathrm{~B}^{* 13: 02}, * 39: 01\end{array}$ \\
\hline SA0124 & $<30$ & 41 & $<30$ & $<30$ & Positive & Yes & $\begin{array}{l}\mathbf{A}^{* 02: 01, * 03: 01} ; \\
\mathbf{B}^{*} 07: 02,{ }^{*} 39: 06\end{array}$ \\
\hline SA0125 & ND & ND & ND & ND & ND & Yes & $\begin{array}{l}\overline{\mathrm{A}^{*} 03: 01},{ }^{*} 03: 02 ; \\
\mathrm{B}^{* 18: 01},{ }^{*} 49: 01\end{array}$ \\
\hline SA0126 & $<30$ & 130 & 100 & 65 & Positive & Yes & $\frac{A^{* 11: 01, * 24: 02 ;}}{B^{*} 08: 01, * 27: 05}$ \\
\hline SA0127 & $<30$ & $<30$ & $<30$ & $<30$ & Negative & No & $\begin{array}{l}\overline{A^{*} 23: 01}, * 34: 02 ; \\
\mathrm{B}^{* 15: 03}, * 58: 01\end{array}$ \\
\hline SA0128 & $<30$ & $<30$ & $<30$ & $<30$ & Negative & Yes & 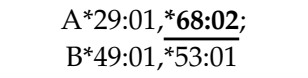 \\
\hline SA0129 & $<30$ & $<30$ & $<30$ & $<30$ & Negative & Yes & $\underline{\mathbf{A}^{*} \mathbf{0 2}: 01 ;} ; \mathrm{B}^{*} 14: 01,{ }^{*} \mathbf{1 5 : 0 1}$ \\
\hline SA0130 & 310 & 110 & $<30$ & $<30$ & Positive & Yes & $\begin{array}{l}\mathbf{A}^{* 03}: 01, * 24: \overline{02} ; \\
\overline{\mathbf{B}^{*} 08: 01,{ }^{*} 40: 01}\end{array}$ \\
\hline SA0131 & 455 & 115 & $<30$ & $<30$ & Positive & Yes & $\begin{array}{l}\overline{\mathrm{A}^{*} \mathbf{0 2 : 0 1}},{ }^{*} \mathbf{6 8 : 0 1} ; \\
\mathrm{B}^{* 15: 17, * 51: 01}\end{array}$ \\
\hline SA0132 & 30 & 440 & $<30$ & $<30$ & Positive & Yes & $\frac{\mathrm{A}^{*} \mathbf{1 1 : 0 1},{ }^{*} \mathbf{2 9 : 0 2}}{\mathrm{B}^{*} 40: 01,{ }^{*} 44: 02}$ \\
\hline SA0133 & 175 & 285 & $<30$ & $<30$ & Positive & Yes & $\mathbf{A}^{* 11: 01,-;}, \mathbf{B}^{*} 35: 01, * 55: 01$ \\
\hline SA0134 & 80 & 260 & $<30$ & $<30$ & Positive & Yes & $\begin{array}{c}\mathrm{A}^{*} 01: 01,{ }^{*} 29: 02 \\
\mathrm{~B}^{*} 44: 03, \overline{, 57: 01}\end{array}$ \\
\hline SA0135 & ND & ND & ND & ND & ND & Yes & 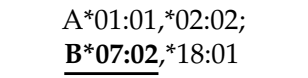 \\
\hline SA0136 & ND & ND & ND & ND & ND & Yes & $\begin{array}{l}\overline{\mathbf{A}^{*} 03: 01} \\
\overline{\mathbf{B}^{*} 08: 01}\end{array}, 25: 01 ;$ \\
\hline SA0137 & 115 & 105 & $<30$ & $<30$ & Positive & Yes & $\begin{array}{l}\overline{A^{*} 30: 02,{ }^{*} 68: 02} ; \\
B^{*} 15: 17,{ }^{*} 18: 01\end{array}$ \\
\hline SA0138 & 555 & 200 & $<30$ & $<30$ & Positive & Yes & 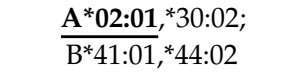 \\
\hline
\end{tabular}


Table 3. Cont

\begin{tabular}{|c|c|c|c|c|c|c|c|}
\hline \multirow{2}{*}{ Patient ID } & \multicolumn{4}{|c|}{ ELISPOT Results (SFUs $/ 10^{6}$ PBMC) } & \multirow{2}{*}{$\begin{array}{l}\text { ELISPOT } \\
\text { Results }\end{array}$} & \multirow{2}{*}{$\begin{array}{l}\text { Peptide } \\
\text { Presentation }\end{array}$} & \multirow{2}{*}{ HLA-Typing } \\
\hline & Pool A & Pool B1 & Pool B2 & Pool B3 & & & \\
\hline SA0139 & 215 & 170 & 50 & 30 & Positive & Yes & 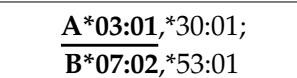 \\
\hline SA0140 & 1025 & 475 & $<30$ & $<30$ & Positive & Yes & $A^{* 68: 01, * 74: 03} ; B * 51: 01$, \\
\hline SA0141 & 935 & 375 & $<30$ & $<30$ & Positive & Yes & $\begin{array}{l}\mathbf{A}^{*} \mathbf{0 2 : 0 1} \\
\overline{\mathbf{B}^{*} 35: 01}\end{array}, * 30: 01$ \\
\hline SA0142 & 295 & 110 & $<30$ & $<30$ & Positive & Yes & $\begin{array}{l}\overline{\mathbf{A}^{*} 03: 01}, * 24: 02 \\
\overline{\mathbf{B}^{*} 07: 02}, * 56: 01\end{array}$ \\
\hline SA0143 & 800 & 275 & $<30$ & $<30$ & Positive & Yes & $\begin{array}{l}\overline{A^{*} 24: 02},{ }^{*} 29: 02 ; \\
B^{*} 07: 02,{ }^{*} 13: 02\end{array}$ \\
\hline SA0144 & 400 & 365 & $<30$ & $<30$ & Positive & Yes & $\begin{array}{l}\overline{\mathrm{A}^{*} 01: 01}, * 30: 02 ; \\
\mathbf{B}^{* 08: 01},{ }^{*} 18: 01\end{array}$ \\
\hline SA0145 & 810 & 640 & $<30$ & $<30$ & Positive & Yes & $\frac{\overline{\mathrm{A}^{*} \mathbf{0 2 : 0 1}},{ }^{*} \mathbf{6 8 : 0 2}}{\overline{\mathrm{B}^{*} 35: 03, * 53: 01}}$ \\
\hline SA0146 & 170 & 70 & $<30$ & $<30$ & Positive & Yes & 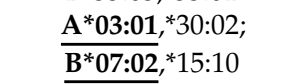 \\
\hline SA0147 & ND & ND & ND & ND & ND & Yes & $\overline{\overline{\mathrm{A}^{*} 68: 02}},{ }^{* 74: 01} ;$ \\
\hline SA0148 & 1160 & 510 & $<30$ & $<30$ & Positive & Yes & $\frac{A^{*} 24: 02,{ }^{*} 68: 02}{B^{*} 35: 02,{ }^{*} 50: 01}$ \\
\hline SA0149 & 365 & 110 & $<30$ & $<30$ & Positive & Yes & $\frac{\mathrm{A}^{*} 02: 01}{\mathrm{~B}^{*} 15: 10},{ }^{*}, 74: 01 ;$ \\
\hline SA0150 & 1695 & 1655 & 30 & 90 & Positive & Yes & $\frac{\mathrm{A}^{*} 03: 01}{\mathrm{~B}^{*} 13: 02},{ }^{*}+27: 05: 01$ \\
\hline SA0151 & 550 & 445 & $<30$ & $<30$ & Positive & Yes & $\begin{array}{l}\mathrm{A}^{*} 01: 01,{ }^{*} 03: 01 \\
\mathbf{B}^{*} \mathbf{0 7 : 0 2 ,}, \mathbf{* 0 8 : 0 1}\end{array}$ \\
\hline
\end{tabular}

Twenty-two patients were investigated for PD-1 protein associated with CD4+ and CD8+ T cells (Table 2). We then compared the percentages of CD4+PD-1+ in ELISPOT-reactive and nonreactive patients; the same comparison was made for CD8+PD-1+ cells (Figure 2). There were no significant differences in these percentages between reactive and nonreactive patients (CD4+T cells: $t=0.65624$, $\mathrm{df}=7.2029, p$-value $=0.5321$ Welch Two Sample $t$-test; CD8+T cells: $t=019264, \mathrm{df}=5.0683$, $p$-value $=0.8547$ Welch Two Sample $t$-test).

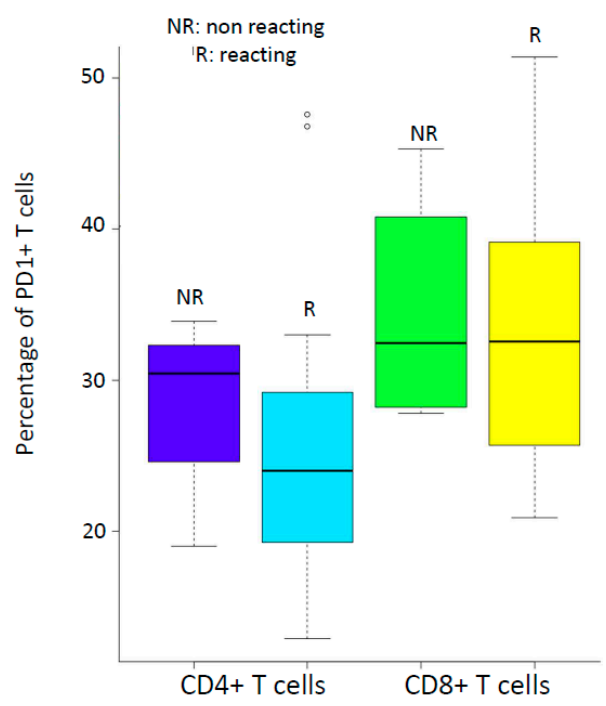

Figure 2. Reactivity to HFVAC peptides by ELISPOT according to the percentages of CD4+ and CD8+ $\mathrm{T}$ cells expressing PD-1. 
Therefore, a high proportion of the population studied was reactive to HFVAC peptides. Of note, patients 111, 116, 117, 119 and 128 showed negative reactivity which was not fully explained by mutations in the archived epitopes or global PD-1 expression on T lymphocytes (data not shown).

\section{Discussion}

The aim of the study was to establish a baseline value of reactivity to the peptides of HFVAC in a population of HIV-1 chronically infected patients on successful ART. The percentage of reactivity was high overall and higher in patients whose HLA alleles belonged to those eligible for the proposed vaccine. This was consistent with reactivity to peptides according to the genetic background of the patients, as hypothesized in the Provir/Latitude45 project. These baseline ELISPOT data should be compared with those obtained in major HIV therapeutic vaccine trials. In the HTI-TriMix trial, where HIV peptides are not directly injected but generated by corresponding mRNAs [9,10], 31\% of the patients were reactive to the so-called IN peptides before initiation of the vaccine program. The percentage of patients included in Vacc-4X [3,4] and who were reactive at baseline was not mentioned in the seminal study [3]; the article by Rockstroh et al. [4] describes a reboost study including patients who had already received Vacc- $4 \mathrm{X}$ five years before; at week 4 of the reboost vaccine trial, less than $10 \%$ of the patients exhibited ELISPOT reactivity to Vacc- $4 \mathrm{X}$ peptides, and this proportion reached $60 \%$ at week 28 . Compared to these baseline evaluated ELISPOT values, the Provir/Latitude45 results seem encouraging, particularly if we consider that the immune system of individuals with higher baseline immune responses while still on cART may be more responsive to immune stimulation by vaccination than those who had lower baseline immune responses [11]. As a different approach, Mothe et al. [12], using recombinant viruses (adenovirus prime-poxvirus MVA boost) expressing a conserved part of the HIV-1 proteome were able to propose the concept that subdominant epitopes in a natural infection can induce strong responses in patients on antiretroviral treatment and efficiently refocus HIV-1-specific T-cells to the protective epitopes delivered by the vaccine; it must be noted that the patients of this latter study were close to HIV-1 primary infection, while our first objective was to address chronically infected patients on ART.

We analyzed the percentages of CD4+ and CD8+ T cells expressing the PD-1 marker, since the latter has been associated with T cell exhaustion in HIV-infected patients, as previously demonstrated in cancer patients $[13,14]$. Although our analysis was limited to 22 patients, the percentages in our HIV-positive patients were much higher than in HIV-negative ones [15] (23.70\% versus $6.2 \%$ for CD4+T cells and $32.90 \%$ versus $16.08 \%$ for CD8+T cells). However, there was still an ELISPOT response to the peptides of HFVAC in patients whose PD-1 expression by T cells exhibited high values. We must underline that we were unable to perform ELISPOT experiments on sorted PD1+ and PD- T CD8+ cells and that we have not investigated other checkpoint markers such as CTLA-4, as an example [13].

Finally, we identified patients without any response to HFVAC peptides. The TCR repertoire for ligation of the peptides associated with HLA alleles is clonal, so one hypothesis is the loss of clones at the moment of primary infection or during the period of chronic productive infection before initiation of ART [16]. Four patients exhibited a very low CD4+ T lymphocytes nadir (ranging from 3 to 14/uL) that could be associated with a profound loss of the TCR repertoire among CD8+ T cells; nevertheless, only one of them (SA0119) was negative by ELISPOT while the three other ones (SA0122, SA0131 and SA0146) were reactive.

In conclusion, this study demonstrated that HIV-1 infected patients on ART who have a genetic background similar to that described in our previous Provir/Latitude45 studies exhibit cellular immune reactivity to the peptides of HFVAC. This paves the way for in vivo studies evaluating vaccine potential of HFVAC in animal models. The next step will investigate the ability of the 15 lipopeptides of HFVAC supplemented with an adjuvant to induce a CD8+T cell response in HIS mice.

Author Contributions: Conceptualization, H.F., J.V. and G.-L.G.; methodology, J.V.; validation, H.F. and J.V.; formal analysis, H.F., J.V. and P.T.; investigation, H.F., S.C., P.R.-P., P.T., G.-L.G., M.H., P.M., F.B. and J.V. resources, H.F.; data curation, H.F. and S.C.; writing-original draft preparation, H.F.; writing-review and editing, H.F., 
S.C., P.R.-P., P.T., G.-L.G., M.H., P.M., F.B. and J.V.; visualization, H.F.; supervision, H.F.; project administration, H.F.; funding acquisition, H.F. All authors have read and agreed to the published version of the manuscript.

Funding: This study was supported by Merck Sharp and Dohme (MSDAvenir grant DS-2016-0005 to H.F.); the funder had no role in study design, data collection and analysis, decision to publish or preparation of the manuscript.

Acknowledgments: ELISPOT and flow cytometry investigations were carried out by the GRIC (Groupe de Recherche en Immunologie Clinique, CHU de Bordeaux) under the supervision of Isabelle Pellegrin and Patrick Blanco. We thank the Medical Doctors involved in the recruitment and follow up of the patients: G. Baulier, N. Bernard, F. Bonnet, D. Bronnimann, H. Chaussade, D. Dondia, P. Duffau, I. Faure, M. Hessamfar, D. Lacoste, C. Martell, P. Morlat, F. Paccalin, M-C. Pertusa, E. Ribeiro, C. Rivoisy, M-A. Vandenhende. H.F. thanks Pierre Dubus, dean of Medicine, for his support and Ray Cooke for copyediting the manuscript. The administrative support of Frederic Perry and Charlotte Terraz (DRCI, CHU de Bordeaux) is greatly acknowledged.

Conflicts of Interest: The authors declare that they have no conflict of interests.

\section{References}

1. Salk, J.; Bretscher, P.A.; Salk, P.L.; Clerici, M.; Shearer, G.M. A strategy for prophylactic vaccination against HIV. Science 1993, 28, 1270-1272. [CrossRef] [PubMed]

2. Fleury, H.; Tumiotto, C.; Bellecave, P.; Recordon-Pinson, P. Therapeutic Vaccine Against HIV, Viral Variability, Cytotoxic T Lymphocyte Epitopes, and Genetics of Patients. AIDS Res. Hum. Retrovir. 2018, 34, 27-30. [CrossRef] [PubMed]

3. Pollard, R.B.; Rockstroh, J.K.; Pantaleo, G.; Asmuth, D.M.; Peters, B.; Lazzarin, A.; Garcia, F.; Ellefsen, K.; Podzamczer, D.; Van Lunzen, J.; et al. Safety and efficacy of the peptide-based therapeutic vaccine for HIV-1, Vacc-4x: A phase 2 randomised, double-blind, placebo-controlled trial. Lancet Infect. Dis. 2014, 14, 291-300. [CrossRef]

4. Rockstroh, J.K.; Asmuth, D.; Pantaleo, P.; Clotet, C.; Podzamczer, D.; Van Lunzen, J.; Arastéh, K.; Mitsuyasu, R.; Peters, B.; Silvia, N.; et al. Re-boost immunizations with the peptide-based therapeutic HIV vaccine, Vacc- $4 \mathrm{x}$, restores geometric mean viral load set-point during treatment interruption. PLoS ONE 2019, 14, e0210965. [CrossRef] [PubMed]

5. Gahéry-Ségard, H.; Pialoux, G.; Charmeteau, B.; Sermet, S.; Poncelet, H.; Raux, M.; Tartar, A.; Lévy, J.P.; Gras-Masse, H.; Guillet, J.G. Multiepitopic B- and T-cell responses induced in humans by a human immunodeficiency virus type 1 lipopeptide vaccine. J. Virol. 2000, 74, 1694-1703. [CrossRef] [PubMed]

6. Deng, K.; Pertea, M.; Rongvaux, A.; Wang, L.; Durand, C.M.; Ghiaur, G.; Lai, J.; McHugh, H.L.; Hao, H.; Zhang, H.; et al. Broad CTL response is required to clear latent HIV-1 due to dominance of escape mutations. Nature 2015, 517, 381-385. [CrossRef] [PubMed]

7. Tumiotto, C.; Alves, B.M.; Recordon-Pinson, P.; Jourdain, M.; Bellecave, P.; Guidicelli, G.L.; Visentin, J.; Bonnet, F.; Hessamfar, M.; Neau, D.; et al. Provir/Latitude 45 study: A step towards a multi-epitopic CTL vaccine designed on archived HIV-1 DNA and according to dominant HLA I alleles. PLoS ONE 2019, 14, e0212347. [CrossRef] [PubMed]

8. Russell, N.D.; Hudgens, M.G.; Ha, R.; Havenar-Daughton, C.; McElrath, M.J. Moving to human immunodeficiency virus type 1 vaccine efficacy trials: Defining $\mathrm{T}$ cell responses as potential correlates of immunity. J. Infect. Dis. 2003, 187, 226-242. [CrossRef] [PubMed]

9. Leal, L.; Guardo, A.C.; Morón-López, S.; Salgado, M.; Mothe, M.; Heirman, C.; Pannus, P.; Vanham, G.; van den Ham, H.J.; Gruters, R.; et al. Phase I clinical trial of an intranodally administered mRNA-based therapeutic vaccine against HIV-1 infection. AIDS 2018, 32, 2533-2545. [CrossRef]

10. De Jong, W.; Leal, L.; Buyze, J.; Pannus, P.; Guardo, A.; Salgado, M.; Mothe, B.; Molto, J.; Moron-Lopez, S.; Galvez, C.; et al. Therapeutic Vaccine in Chronically HIV-1-Infected Patients: A Randomized, Double-Blind, Placebo-Controlled Phase IIa Trial with HTI-TriMix. Vaccines 2019, 7, 209. [CrossRef]

11. Huang, Y.; Pantaleo, G.; Tapia, G.; Sanchez, B.; Zhang, L.; Trondsen, M.; Hovden, A.-O.; Pollard, R.; Rockstroh, J.; Ökvist, M.; et al. Cell-Mediated Immune Predictors of Vaccine Effect on Viral Load and CD4 Count in a Phase 2 Therapeutic HIV-1 Vaccine Clinical Trial. EBioMedicine 2017, 24, 195-204. [CrossRef] 
12. Mothe, B.; Manzardo, C.; Sanchez-Bernabeu, A.; Coll, P.; Morón-López, S.; Puertas, M.C.; Rosas-Umbert, M.; Cobarsi, P.; Escrig, R.; Jose, M.; et al. Therapeutic Vaccination Refocuses T-cell Responses Towards Conserved Regions of HIV-1 in Early Treated Individuals (BCN 01 study). EClinicalMedicine 2019, 11, 65-80. [CrossRef] [PubMed]

13. Mylvaganam, G.; Yanez, A.G.; Maus, M.; Walker, B.D. Toward T Cell-Mediated Control or Elimination of HIV Reservoirs: Lessons From Cancer Immunology. Front. Immunol. 2019, 10, 2109. [CrossRef] [PubMed]

14. Day, C.L.; Kaufmann, D.E.; Kiepiela, P.; Brown, J.A.; Moodley, E.S.; Reddy, S.; Mackey, E.W.; Miller, J.D.; Leslie, A.J.; DePierres, C.; et al. PD-1 expression on HIV-specific T cells is associated with T-cell exhaustion and disease progression. Nature 2006, 443, 350-354. [CrossRef] [PubMed]

15. Booiman, T.; Wit, F.W.; Girigorie, A.F.; Maurer, M.; De Francesco, D.; Sabin, C.A.; Harskamp, A.M.; Prins, M.; Franceschi, C.; Deeks, S.G.; et al. Terminal differentiation of T cells is strongly associated with CMV infection and increased in HIV-positive individuals on ART and lifestyle matched controls. PLOS ONE 2017, 12, e0183357. [CrossRef] [PubMed]

16. Meyer-Olson, D.; Brady, K.W.; Bartman, M.T.; O'Sullivan, K.M.; Simons, B.C.; Conrad, J.A.; Duncan, C.B.; Lorey, S.; Siddique, A.; Draenert, R.; et al. Fluctuations of functionally distinct CD8+ T-cell clonotypes demonstrate flexibility of the HIV-specific TCR repertoire. Blood 2006, 107, 2373-2383. [CrossRef] [PubMed]

Publisher's Note: MDPI stays neutral with regard to jurisdictional claims in published maps and institutional affiliations.

(C) 2020 by the authors. Licensee MDPI, Basel, Switzerland. This article is an open access article distributed under the terms and conditions of the Creative Commons Attribution (CC BY) license (http://creativecommons.org/licenses/by/4.0/). 